\title{
sciendo
}

\section{Genetic Markers Associated with Power Athlete Status}

\author{
by \\ Agnieszka Maciejewska-Skrendoㅁ, Paweł Cięszczyk1, Jakub Chycki², \\ Marek Sawczuk', Wojciech Smótka4
}

\begin{abstract}
Athletic performance is a multifactorial phenotype influenced by environmental factors as well as multiple genetic variants. Different genetic elements have a great influence over components of athletic performance such as endurance, strength, power, flexibility, neuromuscular coordination, psychological traits and other features important in sport. The current literature review revealed that to date more than 69 genetic markers have been associated with power athlete status. For the purpose of the present review we have assigned all genetic markers described with reference to power athletes status to seven main groups: 1) markers associated with skeletal muscle structure and function, 2) markers involved in the inflammatory and repair reactions in skeletal muscle during and after exercise, 3) markers involved in blood pressure control, 4) markers involved in modulation of oxygen uptake, 5) markers that are regulators of energy metabolism and cellular homeostasis, 6) markers encoding factors that control gene expression by rearrangement of chromatin fibers and mRNA stability, and 7) markers modulating cellular signaling pathways. All data presented in the current review provide evidence to support the notion that human physical performance may be influenced by genetic profiles, especially in power sports. The current studies still represent only the first steps towards a better understanding of the genetic factors that influence power-related traits, so further analyses are necessary before implementation of research findings into practice.
\end{abstract}

Key words: genetic markers, genetic polymorphism, power athletes, strength athletes, athletes status.

\section{Introduction}

Athletic performance is a multifactorial phenotype influenced by environmental factors as well as multiple genetic variants (i.e., polymorphisms) acting as key intrinsic factors. The world-wide studies have showed that genetic elements have a great influence over components of athletic performance such as endurance, strength, power, flexibility, neuromuscular coordination, psychological traits and other features important in sport. In sport genomics studies involving athletes of many disciplines, the heritability of athlete status was estimated at $66 \%$ with the detailed rates differing depending on traits; for example, the heritability of muscle strength has been shown to range from approximately 30 to $80 \%$ in various phenotypes such as isometric knee strength, handgrip strength, and elbow flexion.

The current literature review revealed that to date more than 69 genetic markers have been associated with power athlete status. However, it should be underlined that the complete genetic profile of elite athletes still remains poorly characterized, and it is likely that each individual polymorphism makes a limited contribution to an elite athletic phenotype. Therefore, when looking

\footnotetext{
1 - Department of Molecular Biology, Faculty of Physical Education, Gdansk University of Physical Education and Sport, Gdansk, Poland.

2 - Faculty of Physical Education, The Jerzy Kukuczka Academy of Physical Education in Katowice, Katowice, Poland.

3 - Unit of Physical Medicine, Faculty of Tourism and Recreation, Gdansk University of Physical Education and Sport, Gdansk, Poland.

${ }^{4}$ - Clinical Department of Laryngology, School of Medicine in Katowice, Medical University of Silesia, Katowice, Poland.
}

Authors submitted their contribution to the article to the editorial board.

Accepted for printing in the Journal of Human Kinetics vol. 68/2019 in August 2019. 
into the group of genetic markers crucial for power athletes, the polymorphic variants encoding diversified products involved in wide variety of cellular processes and pathways should by analyzed. For the purpose of the present review, we have assigned all genetic markers described with reference to power athletes status to seven main groups: 1) markers associated with skeletal muscle structure and function, 2) markers involved in the inflammatory and repair reactions in skeletal muscle during and after exercise, 3) markers involved in blood pressure control, 4) markers involved in modulation of oxygen uptake, 5) markers that are regulators of energy metabolism and cellular homeostasis, 6) markers encoding factors that control gene expression by rearrangement of chromatin fibers and mRNA stability, and 7) markers modulating cellular signaling pathways.

\section{1) Markers associated with skeletal muscle structure and function}

Proper skeletal muscle structure and function are definitely one of the most important features in the context of athletic performance, especially taking into account the aspects associated with developing power/strength phenotypes. Muscle structure and function may be controlled at the genetic level by many different genes - its polymorphic variants may serve as useful markers of power athletes status.

One of the first genetic markers associated with athletic performance was a common genetic variation in the ACTN3 gene (location: 11q13.1) that results in the replacement of an arginine (Arg or R) with a stop codon at amino acid 577 (C-to-T transition in exon 16; rs1815739; R577X). The ACTN3 gene encodes the protein alpha-actinin-3, a sarcomeric protein that is the predominant protein component of the sarcomeric $\mathrm{Z}$ line in skeletal muscle fibres, where they form a lattice structure that anchors together actin containing thin filaments and stabilizes the muscle contractile apparatus. ACTN3 is expressed in fast, type II fibers, where it plays an important role in the generation of explosive and powerful muscle contractions. The 577X allele contains a sequence change that completely prevents the production of functional $\alpha$-actinin-3 protein. Several case-control studies have reported that the ACTN3 RR genotype is over-represented or the ACTN3 XX genotype is under-represented in strength/sprint athletes in comparison with controls. Yang et al. (2003) for the first time showed that the frequency of the ACTN3 $\mathrm{XX}$ genotype was reduced in Australian power athletes compared to controls, whereas none of the Olympians or female power athletes had an XX genotype. These findings have been supported by independent replications in case-control studies of elite Finnish sprint athletes (Niemi and Majamaa, 2005), elite Greek track and field athletes (Papadimitriou et al., 2008), elite-level strength athletes from across the United States (Roth et al., 2008), Russian power-oriented athletes (Druzhevskaya et al., 2008), Italian artistic gymnasts (Massidda et al., 2009), Taiwanese sprint swimmers (Chiu et al., 2011), Israeli sprinters (Eynon et al., 2009), Russian short-distance speed skaters (Ahmetov et al., 2011), Polish poweroriented athletes (Cięszczyk et al., 2011b) and Japanese sprint/power athletes (Mikami et al., 2014). It should be noted that several studies reported no association between the ACTN3 R577X polymorphism and power athlete status.

The appropriate content and structure of cytoskeletal proteins present in the muscle tissue is crucial for proper muscle function. One of such cytoskeletal proteins is dystrophin which is found at the inner surface of muscle fibers and is part of the dystrophin-glycoprotein complex, that bridges the inner cytoskeleton (F-actin) and the extracellular matrix. The dystrophin $(D M D$; location: Xp21.2) gene is the largest gene found in nature (2.4 $\mathrm{Mb}$ ). Dystrophin RNA is differentially spliced, producing a range of different transcripts, encoding a large set of protein isoforms. The comparison of genetic profiles of two groups of athletes performed during a genome-wide association study of elite Russian strength/power and endurance athletes that aimed to identify common genetic variants associated with elite athlete status (Naumov et al., 2014) revealed that the rare $D M D$ rs939787 $\mathrm{T}$ allele was overrepresented in strength/power athletes compared to endurance athletes and controls, indicating that $D M D \quad$ rs939787 $\quad \mathrm{T}$ allele is favorable for strength/power performance.

Human COTL1 gene (location: 16q24.1) was also identified as a filamentous actin (F-actin) binding protein which regulates the actin cytoskeleton. This protein also interacts with a 5lipoxygenase (5LO) binding partner, which is the 
first committed enzyme of leukotrien biosynthesis in the leukocytes. In a genome wide association study (GWAS) of Ischenko et al. (2015) the COTL1 rs7458 $\mathrm{T}$ allele was in the group of SNPs that were correlated with power athlete status and subsequently replicated in all three subgroups of power athletes (regardless of their sports level). The molecular aspects of this SNP have not been yet described and further studies on the role of rs7458 alleles are required.

Another cytoskeletal protein that occurs together with actin myofilaments, and binds to myosin phosphatase and RhoA is a myosin phosphatase Rho interacting protein (MPRIP). This protein is known as a fusion partner of the receptor TK gene NTRK1. A specific domain at the amino terminus of MPRIP has been shown to mediate actin binding in vivo. The human MPRIP gene is located in the $17 \mathrm{p} 11.2$ locus. The genome wide analyses revealed that the MPRIP rs6502557 A allele was positively correlated with predisposition to strength and power sports, probably by influencing muscle contraction (Egorova et al., 2015). Considering that this observation has not been replicated, it needs further investigation and confirmation.

The next markers associated with skeletal muscle function are those located in genes encoding factors involved in skeletal muscle contraction processes. A member of this group is a substitution G to A (rs1799938) in the CACNG1 gene (location: 17q24.2) that results in the amino acids change of Gly to Ser in position 196 located in a transmembrane part of the encoded protein. This protein is a gamma1 subunit (muscle-specific isoform) that is a part of voltage-dependent calcium channels, playing a role in maintaining the calcium homeostasis and excitation-contraction coupling. The 196Ser allele has been recognized as significant and associated with elite strength athlete status in a GWAS of Russian athletes (Egorova et al., 2015). However, the detailed impact of Gly196Ser substitution on strength properties need to be established.

It is worth to notice that calcium homeostasis is directly controlled by the receptor for the peptide hormone calcitonin, encoded by CALCR gene (location: 7q21.3). Stimulation of the calcitonin receptor also regulates the osteoclastmediated bone resorption. Another GWAS performed by Ischenko et al. (2005) in Russian power athletes with a speed/strength component, endurance athletes and controls revealed that the CALCR G allele of rs17734766 was associated with power athlete status. The genetic variation within the CALCR gene has been correlated with bone mineral density and onset of osteoporosis. It might be speculated that this SNP would play a role in regulation of bone mass in humans. Thus, athletes carrying the specific form of the CALCR gene might benefit from having stronger bones that are better adjusted to withstand extreme forces and transfer loads over the normal loading conditions. This aspect is especially important for athletes performing strength sports such as powerlifting or weightlifting, for which tremendous weight loads are transferred throughout the whole training program and during competition.

The transmembrane cotransport of lactate and protons into or out of skeletal muscle is another factor influencing muscle contraction processes. The studies of professional athletes have revealed that lactate transport rates depend on a common A1470T (Glu490Asp) polymorphism (rs1049434) that leads to the replacement of glutamic acid with aspartic acid and has been identified in the MCT1 gene (location: 1p13.2), encoding monocarboxylate (lactate/pyruvate) transporter 1. The MCT1 is more prevalent in Type I oxidative muscle fibers. Carriers of the minor $\mathrm{T}$ allele have $60-65 \%$ reduced lactate transport rates and experience higher blood lactate accumulations during high intensity circuit weight training, compared to carriers of the A allele. In a study by Sawczuk et al. (2015), it was shown that the MCT1 $\mathrm{T}$ allele was associated with sprint/power performance in a recessive genetic model and the TT genotype was more prevalent in sprint/power athletes compared to both controls and endurance athletes, suggesting that MCT1 A1470T might be one polymorphism that influences athletic sprintpower performance in the Polish population. However, this observation has not been confirmed in other studies.

A separate group of factors that play an important role in growth and can induce hypertrophy of skeletal muscle and other target tissues are insulin-like growth factors. Insulin-like growth factor 1 (IGF-1) is encoded by the IGF1 gene (location: 12q23.2). The effects of IGF-1 are mediated by the insulin-like growth factor 1 receptor (IGF-1R; encoded by IGF1R, location: 
15q26.3) that is a transmembrane receptor. Mice lacking the IGF-1 receptor die late in development, and show a dramatic reduction in body mass, testifying to the strong growth-promoting effect of this receptor. Mice carrying only one functional copy of IGF-1R are normal, but exhibit an $\sim 15 \%$ decrease in body mass. The minor $\mathrm{T}$ allele of the C1245T (rs35767 C/T) IGF1 polymorphism was found to be associated with higher circulating IGF1 levels, and possibly with increased muscle mass. Ben-Zaken et al. (2013b) in a study of power athletes found that the IGF1 rs35767 T allele was more frequent in the top-level Israeli power athletes (international and Olympic level) compared to national level athletes. In the second study of Israeli power athletes, Ben-Zaken et al. (2015b) showed that IGF1R C allele of the rs1464430 A/C polymorphism was more prevalent in elite power athletes in comparison with less professional power athletes or endurance athletes. The authors also concluded that the IGF1R AA genotype might be beneficial for endurance-type sports.

Insulin like growth factor 2 (IGF2) is a protein hormone that, along with IGF1, also plays a pivotal role in skeletal muscle growth and differentiation. IGF2 is structurally similar to insulin, and act as a growth-regulating, insulin-like and mitogenic factor. The IGF2 is encoded by the IGF2 gene (location: 11p15.5). IGF2 is maternally imprinted and paternally expressed what indicates its key role as a regulating factor in fetal growth and development. Several SNPs of the IGF2 gene (rs3213221, rs680, rs7924316) were associated with loss of muscle strength directly after exertional muscle damage. The IGF2 rs680 A/G polymorphism was associated with changes in the levels of IGF2 mRNA. Particularly, significantly higher levels of IGF2 mRNA were observed for the $\mathrm{G}$ allele when compared with the A allele. It was then suggested that this polymorphism played a role in the IGF2 transcription. A study by BenZaken et al. (2017) that aimed to assess the frequency distribution of the IGF2 rs680 A/G polymorphism among Israeli athletes showed that the frequency of $G$ allele carriers was significantly greater among top compared to national-level track and field sprinters and jumpers. The rs680 GG genotype frequency was significantly greater among track and field sprinters and jumpers compared to weight lifters and among top-level sprinters and jumpers compared to top-level weight lifters.

Other studies suggested that neuromuscular development and maintenance might be influenced by a ciliary neurotrophic factor (CNTF). This factor is expressed in glial cells within the central and peripheral nervous systems. The CNTF stimulates gene expression, cell survival or differentiation in a variety of neuronal cell types. All CNTF actions are triggered by binding to its receptor: the CNTFR, of which expression is relatively high in skeletal muscle. Moreover, the analysis with use of the rat model revealed that the expression of CNTFR mRNA was greater in fasttwitch muscle than in slow-twitch muscle. In mice with a blocked CNTFR gene a severe motor neuron deficit has been observed. The report of MiyamotoMikami et al. (2016) indicated that C/T substitution (rs41274853) in the CNTFR gene (location: 9p13.3) could influence sprint/power athletic status. The TT genotype was significantly more frequent among international sprint/power athletes than in controls. Furthermore, in non-athletic men, TT genotype carriers exhibited significantly greater leg extension power and vertical jump performance. All these observations implicate that rs41274853 SNP may be associated with sprint/power athletes status, but without more comprehensive studies and confirmations of the trends in allele and genotype frequencies, it will be rather a potential than a true marker.

\section{2) Markers involved in the inflammatory and repair reactions in skeletal muscle during and after exercise}

Inflammation may serve as a mechanism promoting skeletal muscle repair and hypertrophy. The inflammation processes are accompanied by upregulation of interleukins production.

The interleukin-1 receptor antagonist (IL1RA) is a member of the interleukin 1 (IL-1) cytokine family and modulates a variety of IL-1 related immune and inflammatory responses. The IL-1RA exerts anti-inflammatory activity by blocking IL-1 receptors and thereby preventing signal transduction of the pro-inflammatory IL-1. The IL-1RA is involved in the inflammatory and repair reactions in skeletal muscle during and after exercise. The IL-1RA is encoded by the IL1RN gene (location: 2q14.2) in close proximity to the genes 
coding for IL-1 $\alpha$ and L-1 $\beta$. The VNTR polymorphism (rs2234663) in intron 2 of the IL1RN gene is caused by the 86-bp variable copy number tandem repeat (two to six repeats), that contains three potential protein-binding sites and therefore may have functional significance. The allele 1 $\left(I L 1 R N^{*} 1\right)$ with 4 repeats is more common than allele $2\left(I L 1 R N^{*} 2\right)$, containing 2 repeats. Alleles with 3,5 and 6 repeats are considered to be rare $(<1 \%)$. In a recent study of Italian athletes and nonathletic controls, Cauci et al. (2010) found that the IL1RN gene VNTR polymorphism was associated with athletic status. The frequencies of the $I L 1 R N^{*} 1 / I L 1 R N^{*} 2$ genotype and IL1RN*2 allele were significantly higher in athletes compared to non-athlete controls. Furthermore, the $I L 1 R N^{*} 1 / I L 1 R N^{*} 2$ genotype was more frequent in competitive than in non-competitive athletes. One might assume that carriers of the IL1RN*2 allele may have an advantage in adaptation to high intensity exercise.

The interleukin-6 (IL-6) (also known as Bcell stimulatory factor-2 (BSF-2) and interferon beta-2) is a pleiotropic cytokine involved in a wide variety of biological functions, including regulation of differentiation, proliferation and survival of target cells, and control for the immune acute-phase response. It is mainly produced by the immune cells, but also is expressed in muscle cells (acts as a "myokine"), and is elevated in the response to muscle contraction. During physical exercise the concentration of plasma IL-6 increases because of its release from muscles, which mediates metabolic processes. The IL-6 is linked to the regulation of glucose homeostasis during exercise and plays a role in the hypertrophic muscle growth with a contribution of satellite cells to this process. The $-174 \quad \mathrm{C} / \mathrm{G}$ (rs1800795) polymorphism in the promoter of the IL6 gene (location: 7p21) alters transcriptional response. There is a genetically determined difference in the degree of the IL- 6 response to stressful stimuli between individuals, with the $\mathrm{C}$ allele found to be associated with significantly lower levels of plasma IL-6. Ruiz et al. (2010) studied the IL6 -174 G/C polymorphism in elite Caucasian Spanish male athletes (endurance athletes and power athletes) and non-athletic controls. The frequencies of the GG genotype and $G$ allele were significantly higher in power-oriented athletes compared with the endurance-oriented athletes and non-athletic controls. These results were replicated by Eider et al. (2013) in a study of Polish power athletes, indicating that the $G$ allele might favor sprint/power sports performance. Not consistent with results of the Spanish and Polish studies, Eynon et al. (2011) reported that there were no differences in allelic and genotypic frequencies of the IL6 -174 C/G polymorphism among elite endurance athletes, power athletes and nonathletic controls (Israeli population).

\section{3) Markers involved in blood pressure control}

The renin-angiotensin system (RAS) is responsible for the regulation of circulatory system function and blood pressure - the main factors deciding the efficiency of the whole body. The RAS also controls skeletal muscle function by regulation of local perfusion, which can modulate metabolic activity. The main effector of the RAS is angiotensin II that is a potent vasopressor and aldosterone-stimulating peptide that controls blood pressure and fluid-electrolyte balance. Besides regulating blood pressure, angiotensin II may influence skeletal muscle function.

$A C E$ is the most frequent investigated gene in the context of genetic conditioning of sportspredispositions, because the product of this gene (ACE; an enzyme converting angiotensin I into II) is acknowledged to be a key-element in RAS. One of the most studied genetic markers associated with athletic performance was the rs4646994 variant resulting in the insertion/deletion (I/D) polymorphism in the $A C E$ gene. The I/D polymorphism of the ACE gene (location: 17q23.3) denotes a substantial individual variation in reninangiotensin system activity with the $\mathrm{D}$ allele being associated with higher ACE activity, resulting in higher angiotensin II levels and a higher proportion of fast, glycolytic, type $2 \mathrm{X}$ muscle fibers; therefore, this allele could favor sprint/power performance. However, reported effects of the $A C E(\mathrm{I} / \mathrm{D})$ polymorphism vary across studies and populations. Several studies have shown the D allele to be associated with greater strength and muscle volumes and an increased percentage of fast-twitch muscle fibers. In addition, the D allele and/or DD genotype was shown to be over-represented in British (Myerson et al., 1999), Russian (Nazarov et al., 2001), European and Commonwealth Caucasian 
swimmers (<400 m) (Woods et al., 2001), Greek sprinters (Papadimitriou et al., 2009), Portuguese (Costa et al., 2009), Spanish strength/power athletes (Boraita et al., 2010) and Caucasian shortand-middle-distance swimmers (Wang et al., 2013a). Contrary to these findings, other report has shown that Korean elite power-oriented athletes had a markedly diminished frequency of the D allele than national level power-oriented athletes or controls (Kim et al., 2010). The same finding was reported when studying power-oriented Lithuanian and Russian athletes and controls (Ginevičienè et al., 2016) as well as in the Iranian population (Shahmoradi et al., 2014). Additionally, Wang et al. (2013b) reported that East Asian shortdistance swimmers had a higher prevalence of the $A C E$ I allele in comparison with controls. Furthermore, several studies of power/sprint athletes have demonstrated no association between the $A C E$ I/D polymorphism and power athlete status.

Another essential component of the reninangiotensin system is the angiotensinogen (AGT) - a serum $\alpha$-globulin formed by the liver. AGT is cleaved by the renin to form biologically inactive angiotensin I, the precursor of active angiotensin II that regulates vascular resistance and sodium homeostasis, and thus determining blood pressure. The AGT is encoded by the AGT gene (location: 1q42.2). Met235Thr polymorphism of the AGT gene leads to the substitution of threonine to methionine at position 235 ( $\mathrm{rs} 699 \mathrm{~T} / \mathrm{C}$ ). The AGT Met235Thr polymorphism was shown to be associated with a left-ventricular mass index increase in a study of young healthy individuals after 17 weeks of training $\left(50-80 \% V_{2} \max\right.$ ) (Lucia et al., 2006). Individuals with the $A G T \mathrm{Thr} / \mathrm{Thr}$ genotype had a significantly greater leftventricular mass index than those with the Met/Met or Met/Thr genotype. Gomez-Gallego et al. (2009b) compared the genotype and allele frequencies for the AGT Met235Thr variation of Caucasian athletes (world-class endurance athletes, power athletes and nonathletic controls). Results revealed a higher percentage of $\mathrm{Thr} / \mathrm{Thr}$ genotype carriers among power athletes than either in controls or an endurance group. These findings were replicated in a study of Polish power athletes (Zarebska et al., 2013). Therefore, it is assumed that the 235Thr allele of the AGT Met235Thr polymorphism might favor power sports performance and this could be attributed to the higher activity of angiotensin II that acts as a growth factor in skeletal muscle.

As it was said above the main effector of the RAS is angiotensin II that acts via two major receptors: AGTR1 (that acts as a vasoconstrictor) and AGTR2 (with vasodilator function). The latter is encoded by the AGTR2 gene (location: Xq23). The rs11091046 A allele was listed as a marker for power traits in different populations. By studying athletes from Russia and Poland, Mustafina et al. (2014) found that the frequency of the AGTR2 A allele was significantly over-represented in female power athletes in comparison to control subjects. However, in the same study the opposite trend was observed with regard to the $C$ allele being overrepresented in the group of male strength athletes. The latest report indicated that Brazilian female power athletes had also a higher frequency of the A-allele. Furthermore, men sprinters with the Aallele showed significantly faster personal best times for the $100 \mathrm{~m}$ than those with the C-allele (Guilherme et al., 2018). On the other hand, the study of Japanese, Russian and Polish track and field sprint/power athletes showed a significantly higher frequency of the $C$ allele in athletes than in controls. However, with regard to respective cohorts, $\mathrm{C}$ allele frequency was higher in Japanese male athletes than in controls, but not in Russian/Polish male athletes. In women, no significant results were obtained (Yvert et al., 2018).

The next important marker, engaged not only in blood pressure control, but also in the regulation of the cardiac, pulmonary, vascular, endocrine and central nervous system is the $\beta-2$ adrenergic receptor (encoded by $A D R B 2$; location: 5q31-q32) - a member of the G protein-coupled receptor superfamily, expressed in many cell types throughout the body. The Gly16Arg SNP (rs1042713 G/A) of the ADRB2 gene and its association with several phenotypes have been described. Specifically, the 16Arg allele was associated with lower receptor density and resting cardiac output. Sawczuk et al. (2013) found that the Gly16 allele and the 27Glu variant of the Gln27Glu (rs1042714 C/G) polymorphism were overrepresented in Polish strength/power athletes compared with controls.

The last marker from this group is the FOCAD gene (location: 9p21.3) encoding 
focadhesin that is engaged in proliferation of epithelial cells and acts as a tumor suppressor. There are some reports raising the possibility that $F O C A D$ influences the heart rate via myocyte turnover and that the effect of $F O C A D$ may change with age, either as a consequence or as a cause of the changing rate of cardiomyocyte renewal with age. The analyses of genetic profiles performed between two groups of elite Russian athletes (power and endurance athletes) as well as between power athletes and controls, revealed that FOCAD rs17759424 C allele was associated with power athlete status (Gabdrakhmanova et al., 2015). In this moment the physiological relevance of rs17759424 SNP is still unknown and more detailed studies are necessary.

\section{4) Markers involved in modulation of oxygen uptake}

The pathways that either deliver oxygen to cells or allow cells to survive oxygen deprivation are crucial in the conditions of physiological stress that is characteristic for the highest rate of oxygen uptake observed during intense exercise in power/strength athletes. Such pathways usually engage many factors that regulate the expression of hundreds of genes involved in angiogenesis, glucose metabolism, glucose transport, vasomotor control, erythropoiesis, and also many of which are implicated in either the delivery of oxygen and nutrients to cells, or controlling cellular utilization of these substrates.

Glycolysis is the central source of anaerobic energy in humans, and this metabolic pathway is regulated under low-oxygen conditions by the transcription factor hypoxiainducible factor $1 \alpha$ (HIF1 $\alpha$; encoded by HIF1A; location: 14q23.2). HIF1 $\alpha$ controls the expression of several genes implicated in various cellular functions including glucose metabolism (glucose transporters and glycolytic enzymes). A missense polymorphism, Pro582Ser, is present in exon 12 ( $\mathrm{C} / \mathrm{T}$ at bp 85; rs11549465). The rare $\mathrm{T}$ allele is predicted to result in a proline to serine change in the amino acid sequence of the protein. This substitution increases HIF $1 \alpha$ protein stability and transcriptional activity, and therefore, may improve glucose metabolism. Ahmetov et al. (2008a) investigated a hypothesis that HIF1A Pro582Ser genotype distribution may differ for controls and Russian sprint/strength athletes, for which anaerobic glycolysis is one of the most important sources of energy for power performance. The frequency of the HIF1A 582Ser allele was significantly higher in weightlifters than in controls and increased with their performance level. These results were replicated in three cohorts of Polish power-orientated athletes (Cieszczyk et al., 2011a), Russian power-oriented athletes (Gabbasov et al., 2013) and Ukrainian poweroriented athletes (Drozdovska et al., 2013), but not in Israeli sprinters (Eynon et al., 2010a).

Endothelial PAS domain protein 1 (EPAS1) is a transcription factor playing a key role in the Hypoxia Inducible Factor (HIF) pathway in blood, which is responsible for activating gene expression in response to hypoxia. EPAS1 plays an important role in the catecholamine and mitochondrial homeostasis, in the control of cardiac output and erythropoietin regulation. Recently, Voisin et al. (2014) investigated the frequencies of the EPAS1 (also known as HIF2A; location: 2p21-p16) gene variants in sprint/power athletes, endurance athletes, and controls from Poland and Russia and found that the rs1867785 G and rs11689011 C alleles were over-represented in the sprint/power athletes.

The oxygen uptake observed in human skeletal muscle during exercise is modulated by nitric oxide (NO). Dietary nitrate supplementation enhances muscle contractile efficiency during knee-extensor exercise and tolerance to highintensity exercise in humans. Therefore, one might anticipate that genetic variation in the endothelial nitric oxide synthase gene (NOS3; location: 7q36; NOS3 generates NO in blood vessels) could be associated with power/sprint performance. Indeed, Drozdovska et al. $(2009,2013)$ have found that the frequency of the NOS3 rs2070744 T (-786 $\mathrm{T} / \mathrm{C}$ polymorphism) allele was significantly higher in Ukrainian power-oriented athletes compared to controls. These results were confirmed in two independent studies of Spanish elite poweroriented athletes and non-athletic controls (Gomez-Gallego et al., 2009a) and Italian poweroriented athletes (Sessa et al., 2011). Furthermore, Sessa et al. (2011) demonstrated that the frequency of the NOS3 rs1799983 Glu298 allele (Glu298Asp polymorphism) was significantly higher in Italian power-oriented athletes in comparison with controls.

Exercise-induced oxidative stress is a state 
that primarily occurs in athletes involved in highintensity sports when prooxidants overwhelm antioxidant defenses to oxidize proteins, lipids and nucleic acids. During exercise, oxidative stress is linked to muscle metabolism and muscle damage, because exercise increases superoxide radicals production. Manganese superoxide dismutase (MnSOD; encoded by the SOD2 gene; location: 6q25.3) catalyzes the dismutation of superoxide radicals in mitochondria by converting anion superoxide into hydrogen peroxide and oxygen. A number of polymorphisms in the SOD2 gene have been described, and one polymorphism in the mitochondrial targeting sequence ( $\mathrm{rs} 4880 \mathrm{C} / \mathrm{T}$; it causes an amino acid change from Ala (A) to $\mathrm{Val}$ (V)) has been demonstrated to have functional significance. Indeed, the $\mathrm{T}$ allele of the Ala16Val polymorphism in the SOD2 gene has been reported to decrease MnSOD efficiency against oxidative stress, which is supported by the observation that the Val-variant decreases formation of the active MnSOD protein in the mitochondrial matrix. In the first study involving Israeli power athletes, BenZaken et al. (2013a) found that the frequency of the SOD2 Ala16 allele was significantly higher in athletes compared with controls. In a subsequent study of Russian and Polish athletes, the frequency of the SOD2 Val/Val genotype was shown to be significantly lower in power/strength athletes compared to controls or athletes involved in lowintensity sports. Furthermore, the SOD2 16Val allele was significantly associated with increased activity of creatine kinase and the creatinine level in athletes (Ahmetov et al., 2014).

\section{5) Markers that are regulators of energy metabolism and cellular homeostasis}

Mitochondria are essential to all higher organisms for sustaining life, and are extremely important in energy metabolism, providing 36 molecules of ATP per glucose molecule in contrast to the two ATP molecules produced by glycolysis. Although most DNA is packaged in chromosomes within the nucleus, mitochondria also possess their own circular DNA: mitochondrial DNA (mtDNA). The 16569-bp human mtDNA contains 13 genes for mitochondrial oxidative phosphorylation (OXPHOS), as well as two ribosomal RNA and 22 transfer RNA genes that are necessary for protein synthesis within mitochondria. Patients with mutations in mitochondrial DNA (mtDNA) commonly present with exercise intolerance, muscle weakness and increased production of lactic acid. At least 4 studies reported association between the 14 mtDNA polymorphisms and power athlete status. Mikami et al. (2011) analyzed the mtDNA polymorphism in 139 Olympic athletes (79 endurance/middle-distance athletes, 60 sprint/power athletes) and 672 controls. Sprint/power athletes displayed a greater proportion of haplogroup F (15.0 vs. $6.0 \% ; p=$ 0.007). In a following study of 185 elite Japanese athletes and 672 controls, 85 sprint/power athletes showed greater frequency of the m.204C, m.151T and m.15314A alleles and dearth of nine alleles (m.16278T, m.5601T, m.4833G, m.5108C, m.7600A, m.9377G, m.13563G, m.14200C, m.14569A) compared with controls (Mikami et al., 2013). Deason et al. (2012) revealed a high level of overrepresentation of the non-African component of MtDNA (non-L/U6 paragroup) in elite AfricanAmerican sprinters $(n=119)$ compared to AfricanAmerican controls $(n=1148)$.

One of the mitochondrial matrix enzymes is the ADP-forming succinyl-CoA synthetase (SCS) that acts as a heterodimer, being composed of an invariant alpha subunit and a substrate-specific beta subunit. The SUCLA2 gene (location: 13q14.2) encodes the beta subunit of the SCS. SCS catalyzes the reversible synthesis of succinyl-CoA from succinate and CoA for activation of ketone bodies and heme synthesis. Defects in the SUCLA2 gene are a cause of myopathic mitochondrial DNA depletion syndrome. The SUCLA2 rs10397 A allele has been recognized as a marker for strength athlete status in the whole genome analyses performed by Egorova et al. (2015) even after applying the corrections criteria. The rs10397 variants are probably important for all athletes, regardless of discipline, because these variants may alter the regulation process of ATP production. However, these speculations are not functionally confirmed, what indicates the need for further investigations.

One of the factors that are indirectly associated with mitochondrial oxidative phosphorylation is the UCPs protein that separates oxidative phosphorylation from ATP synthesis with energy dissipated as heat. Uncoupling protein-2 (UCP2) is one of the inner mitochondrial membrane proteins involved in energy expenditure that facilitates the transfer of anions 
from the inner to the outer mitochondrial membrane and the return transfer of protons from the outer to the inner mitochondrial membrane. The UCP2 gene (location 11q13.4) is expressed in many tissues, with the greatest expression in skeletal muscle. The polymorphism C/T (rs660339) in the UCP2 gene resulting in Ala55Val amino acids substitution has been described as associated with power athletes status: the C allele (Ala55) was over-represented among Italian power athletes (Sessa et al., 2011).

However, not only sequence variants within genes encoding factors that are involved in ATP production are good markers of energy metabolism. Among many specific genes that have been associated with performance due to their role in energy homeostasis in muscle cells, the musclespecific creatine kinase (CKM) gene (location: 19q13.32) is an important candidate gene. Creatine kinase catalyzes the reversible transfer of energyrich phosphate from creatine phosphate to adenosine diphosphate, thus forming ATP. CKM is an essential enzyme for the maintenance of energy in the muscle cell during activity involving muscle contraction. The most frequently analyzed genetic variant of this gene is a polymorphism rs8111989 located in the 3 UTR. The A/G variants of this SNP have been associated with skeletal muscle performance in humans; they are correlated with physical performance and contribute to differences in maximum oxygen uptake $\left(\mathrm{VO}_{2 \max }\right)$ responses during power or endurance training. The metaanalyses of publications on the CKM rs8111989 A/G allele or genotype differences between power and general controls found that power athletes had a significantly higher frequency of the G and GG genotype compared to controls (Chen et al., 2017).

Another important regulator of muscle energy metabolism is adenosine monophosphate deaminase (AMPD). This enzyme displaces the equilibrium of the myokinase reaction towards ATP production by converting AMP into inosine monophosphate (IMP) with liberation of ammonia. The human AMPD1 gene (location: 1p13) produces isoform $\mathrm{M}$, myoadenylate deaminase, and is expressed at a high level predominantly in adult skeletal muscle. Homozygotes for the rs17602729 mutation $(34 \mathrm{C}>\mathrm{T} ; \mathrm{G} \ln 12 \mathrm{X})$ of the $A M P D 1$ have extremely low skeletal muscle AMPD activities, individuals with one normal and one mutant allele have intermediate activities, and those with two
AMPD1 normal alleles have high activities. There are reports suggesting that AMPD1 deficiency could have a detrimental effect on sprint/strength performance. Indeed, Cieszczyk et al. (2012b) showed that Polish power-oriented athletes had a significantly lower frequency of the AMPD1 $12 \mathrm{X}$ allele than controls. These results were replicated in cohorts of Russian power-oriented athletes (Fedotovskaya et al., 2013) and Lithuanian sprint and power athletes (Ginevičienè et al., 2014).

Carnosine ( $\beta$-alanyl-L-histidine) also plays an important role in the context of energy balance, particularly during exercise, especially in muscles that rely on anaerobic metabolism to fuel their activity for high-intensity contractions. Carnosine is a dipeptide synthesized from B-alanine and histidine, found in the skeletal muscle. Variability in muscle carnosine content between individuals exists and may be explained by different factors, for example activity of carnosine-degrading enzymes named carnosinases. A variation in carnosinases activity could directly or indirectly affect muscle carnosine content. Two forms of carnosinases (and their genes in locus: 18q22.3) have been identified: CNDP1 (found in serum, encoded by CNDP1) and CNDP2 (tissue carnosinase, encoded by CNDP2). The study performed in a large Brazilian cohort of athletes revealed that three SNPs (CNDP1 rs2887, rs2346061 and CNDP2 rs3764509) were associated with power athlete status. The carriers of the rs 2887 A allele, rs2346061 C allele and rs3764509 G allele had an increased odds ratio of being a power athlete (Guilherme and Lancha, 2017). Such a result suggests that polymorphisms in carnosinases genes may be included into the group of power markers, however, this assumption needs replication studies in different populations.

The regulation of energy metabolism and homeostasis is a very complex problem, involving many levels of cellular control: from receptors of the cell surface through intracellular second messengers to transcription factors that regulate the expression of particular genes and modulate the metabolic pathways in a long-term manner. PPAR $\alpha$ is such a ligand-activated transcription factor that regulates the expression of genes involved in fatty acid uptake and oxidation, glucose and lipid metabolism, left ventricular growth and control of body weight. The hypothesis that intron $7 \mathrm{C}$ allele is associated with the 
hypertrophic effect due to influences on cardiac and skeletal muscle substrate utilization was supported by the findings that the PPARA C allele was over-represented in Russian power-oriented athletes and associated with an increased proportion of fast-twitch muscle fibres in $m$. vastus lateralis of male controls (Ahmetov et al., 2006). Furthermore, in a study of Lithuanian athletes, Ginevičiene et al. (2010) showed that male athletes with PPARA CC and PPARA GC genotypes had significantly higher muscle mass and single muscular contraction power (measured by vertical jump test) than GG homozygotes. The frequency of the PPARA C allele was also significantly higher in Lithuanian power-oriented athletes and athletes with mixed aerobic/anaerobic activity in comparison with controls. It was also shown that the male carriers (middle school-age boys) of the PPARA C allele demonstrated the best results of handgrip strength testing than GG homozygotes (Ahmetov et al., 2013; Bonisławska et al., 2018). However, Broos et al. (2013) did not find any association between the PPARA rs4253778 G/C polymorphism and muscle strength characteristics in non-athletic young men. There were no differences in allelic frequencies between Israeli sprinters and controls (Eynon et al., 2010b).

The next representative of the PPAR family is the peroxisome proliferator-activated receptor $\gamma$ (PPAR $\gamma$; encoded by PPARG; location: $3 \mathrm{p} 25)$ that plays a critical physiological role as a central transcriptional regulator of adipogenic and lipogenic programs, insulin sensitivity and glucose homeostasis. The 12Ala variant of the PPARG gene Pro12Ala polymorphism (rs1801282C/G) is associated with decreased receptor activity and improved insulin sensitivity. The carriers of the 12Ala allele ( $G$ allele) show higher rates of skeletal muscle glucose uptake and a greater crosssectional area of muscle fibers (Ahmetov et al., 2008b). In a study of Russian power-oriented athletes, a higher frequency of the PPARG 12Ala allele compared to controls was reported (Ahmetov et al., 2008b). These results were replicated in two studies involving Polish strength athletes (Maciejewska-Karlowska et al., 2013) and Ukrainian power-oriented athletes (Drozdovska et al., 2013).

The PGC $1 \alpha$ and PGC1 $\beta$ proteins (encoded by the PPARGC1A, location: $4 \mathrm{p} 15.2$ and PPARGC1B genes, location: $5 \mathrm{q} 32$, respectively) are transcriptional coactivators of many different transcription factors and nuclear receptors. They act through direct interaction with a transcription factor, control the energy expenditure and regulate fat oxidation as well as non-oxidative glucose metabolism. PGC1 $\alpha$ and PGC1 $\beta$ are powerful regulators of mitochondrial biology in the heart, acting by broadly regulating gene expression from both nuclear and mitochondrial genomes - in this way PGC1 $\alpha$ andPGC1 $\beta$ play a critical role in mitochondrial metabolism. The allelic variations in their genes increase the risk of the development of 2 diabetes mellitus and obesity. It has been shown that the PPARGC1A rs8192678 AA genotype (that is characteristic for PGC1 $\alpha$ proteins with Ser in the 482 position) is more favorable for Russian and Lithuanian powerlifters compared to controls (Ginevičienè et al., 2016). However, this trend was not found in a previous study performed in the large group of Polish and Russian strength athletes (Maciejewska et al., 2012). Furthermore, in the GWAS that compared endurance versus power athletes and controls, the rs $10060424 \mathrm{C}$ allele of PPARGC1B gene was designated as associated with power athlete status (Ischenko et al., 2015). It may be speculated that the importance of these two SNPs in power athletes results from their involvement in carbohydrate/lipid metabolism, however, the detailed mechanism of their molecular impact remains unknown.

Taking into account that some enzymes, such as 17-beta-hydroxysteroid dehydrogenases (HSD17B14), are primarily involved in metabolism of steroids at the $\mathrm{C} 17$ position and also of other substrates, like fatty acids, prostaglandins, and xenobiotics, it may be assumed that they will play a role in energy balance maintenance. Particularly, 17-beta-hydroxysteroid dehydrogenases catalyze the stereospecific oxidation/reduction at carbon $17 \beta$ of androgens and estrogens. Upon receptor binding, the 17 $\beta$-hydroxy conformation of androgens and estrogens triggers a greater biological response than the corresponding ketoconformation of the steroids and, in this way, the HSD17B14 enzyme may be considered as an important mediator in pre-receptor regulation of sex hormone action. In the genome wide association study of Ischenko et al. (2015) the HSD17B14 gene (location: 19q13.33) rs7247312 G allele was annotated to the group of the markers 
associated with power athlete status along with the suggestion that it might be involved in alteration of steroids metabolism.

Another enzyme of interest is a TPK1 protein encoded by the TPK1 gene (location: 7q35). TPK1 is a cellular enzyme involved in the regulation of thiamine metabolism. It functions as a homodimer and catalyzes the conversion of thiamine (a form of vitamin B1) to thiamine pyrophosphate, a cofactor for enzymes important in a range of fundamental processes such as cellular respiration, glycolytic and energy production pathways as well as in providing substrates for synthesis of nucleic acids, nucleotides, fatty acids and steroids. A number of defects in thiamine transport and metabolism are known - in this group defects in the TPK1 gene are a cause of thiamine metabolism dysfunction syndrome-5. The comparison of genetic profiles of two groups of elite Russian athletes (power vs. endurance and between power athletes and controls) identified the TPK1 rs10275875 C allele as a genetic marker associated with power athlete status (Gabdrakhmanova et al., 2015). The role of thiamin pyrophosphokinase 1 in vitamin B1 metabolism suggests that the variation of the TPK1 gene may be important for power athletes, because $B$ vitamins are involved in energy production and tissue repair and their normal metabolism is necessary for the appropriate recovery of the body after exercise.

The protein encoded by GALNT13 (location:2q24.1) may also be involved in metabolism and energy pathways. The product of this gene is a member of the GALNT family, which initiate O-linked glycosylation of mucins by the initial transfer of $\mathrm{N}$-acetyl-galactosamine with an alpha-linkage to a serine or threonine residue and thus catalyzes the initial reaction in O-linked oligosaccharide biosynthesis. GALNT13 is highly expressed in brain, B cells, kidney and liver. By performing three GWASs of elite Jamaican, African-American and Japanese sprint athletes and their matched controls and subsequent metaanalysis, Wang et al. (2014) found that the GALNT13 G allele of rs10196189 A/G polymorphism was significantly over-represented in elite sprinters compared with controls.

6) Markers encoding factors that control gene expression by rearrangement of chromatin fibers and mRNA stability
DNA methylation is a major epigenetic modification that suppresses gene expression by modulating the access of the transcription machinery to the chromatin or by recruiting methyl binding proteins. It has been shown that exercise-induced acute gene activation was associated with a dynamic change in DNA methylation in skeletal muscle and it has been suggested that DNA hypomethylation is an early event in contraction-induced gene activation (Barrès et al., 2012). More specifically, whole genome methylation was decreased in skeletal muscle biopsies obtained from healthy sedentary men and women after acute exercise. Furthermore, recent findings suggest that DNA hypomethylation induces the activation of myogenic factors determining proliferation and differentiation of myoblasts promoting muscle growth and increases of muscle mass (Terruzzi et al., 2011).

Since components of the folate-pathway (homocysteine cycle) are involved in DNA methylation/demethylation processes (and synthesis of nucleotides), Terruzzi et al. (2011) investigated whether polymorphisms of the folatepathway genes affecting gene expression and protein stability, probably responsible of DNA methylation deficiency, were associated with athlete status. The polymorphic variants A1298C (rs1801131 A/C) of 5,10-methylenetetrahydrofolate reductase (MTHFR; location: 1p36.3), A2756G (rs1805087 A/G) of methionine synthase (MTR; location: 1q43), A66G (rs1801394 A/G) of methionine synthase reductase (MTRR; location: 5 15.31) genes were determined in athletes and control subjects. The frequencies of MTHFR rs1801131 C, MTR rs1805087 G and MTRR rs1801394 G alleles (probably associated with a reduced DNA methylation capacity) were significantly higher in athletes compared with controls (Terruzzi et al., 2011). Recently, Zarebska et al. (2014) replicated the results of association between the MTHFR rs1801131 C allele and power/strength athlete status in a study of power/strength athletes from Poland and Russia. Taken together, these data indicate that elite athletes have a genetic predisposition to DNA hypomethylation and synthesis (factors leading to myogenic differentiation stimulation, muscle mass increases and induction of genes involved in energy metabolism). 
Modulation of genes expression also occurs by regulation of mRNA translation and stability. One of the factors engaged in such a process is ROQUIN - a protein containing RINGtype and C3H1-type zinc finger motifs. It is encoded by the $R C 3 H 1$ gene (location: 1q25.1). The mechanism of ROQUIN molecular action is based on recognition and binding to a constitutive decay element (CDE) in the 3 UTR of mRNAs, leading to mRNA deadenylation and degradation. ROQUIN plays a crucial role in the innate and adaptive immune system by influencing macrophage function and the homeostasis of $\mathrm{T}$ and $\mathrm{B}$ cells. Moreover, the activity of ROQUIN is pivotal for Tcell-dependent B-cell response against infection. Impairment in ROQUIN activity results in autoimmunological diseases, for example immunodeficiency. The RC3H1 rs767053 G allele has been described as a marker for power performance in a genome wide association study of Russian athletes (Ischenko et al., 2015). The molecular mechanism of rs767053 impact on ROQUIN activity has not been yet described and in vitro studies are required.

The next member of the zinc finger proteins family is a product encoded by ZNF423 gene (location: 16q12.1). This is a nuclear protein that belongs to the group of Kruppel-like C2H2 zinc finger proteins. It functions as a DNA-binding transcription factor using distinct zinc fingers in different signaling pathways. Thus, it is thought that this gene may have multiple roles in signal transduction during development. Moreover, it has been revealed that the zinc finger protein 423is a transcriptional regulator involved in preadipocyte determination. The molecular analysis revealed the ZFP423 protein as a factor enriched in preadipose versus non-preadipose fibroblasts. The next step of differentiation of committed preadipocytes to adipocytes is controlled by PPAR $\gamma$ and several other transcription factors. In a mouse model it has been shown that the Zfp423 protein regulates Pparg expression. Furthermore, both brown and white adipocyte differentiations are markedly impaired in Zfp423-deficient mouse embryos. In the GWAS performed in a large group of Russian athletes the ZNF423 rs11865138 C allele was described as a marker of power athlete status (Ischenko et al., 2015).

Another genetic marker that controls gene expression is the protein encoded by MED4 gene. The product of this gene is a mediator complex subunit 4 , which is a component of the vitamin D receptor-interacting protein (DRIP) complex functioning as a nuclear receptor coactivator. The DRIP complex interacts with DNA-binding genespecific transcription factors to modulate transcription by RNA polymerase II and in this way is capable of activating nuclear receptors in a ligand-dependent manner. Binding to ligands induces conformational changes in the nuclear receptors that enable the nuclear receptors to interact with several types of coactivators, such as DRIP that are critical for transcription activation. Egorova et al. (2015) revealed that the MED4 gene (location: 13q14.2) rs7337521 $\mathrm{T}$ allele is associated with elite strength athlete status. In this moment, there is very limited information on the rs7337521 SNP with regard to its physiological or molecular relevance.

The equally important way of genes expression control is the rearrangement of chromatin fibers. The WAPL protein is a cohesinbinding protein that promotes sister-chromatid resolution in mitotic prophase. Cohesin complexes are involved in arrangement of chromatin fibers into higher-order structures. It has been shown that depletion of the WAPL protein stably locks cohesin on DNA, leads to clustering of cohesin in axial structures, and causes chromatin condensation in interphase chromosomes. Furthermore, it has been revealed that regulation of cohesin-DNA interactions by WAPL is important for embryonic development and cell cycle progression. In mitosis, WAPL-mediated release of cohesin from DNA is essential for proper chromosome segregation and protects cohesin from cleavage by the protease separase, thus enabling mitotic exit in the presence of functional cohesin complexes. In the GWAS of Russian athletes, encompassing strength and endurance athletes, it was suggested that WAPL gene (location: 10q23.2) rs4934207 C allele was associated with elite strength athlete status, what was confirmed in the same study after applying correction criteria (Egorova et al., 2015). However, to establish the role of rs4934207 SNP as a true marker of strength abilities, more detailed studies of molecular as well as physiological aspects are required. 


\section{7) Markers modulating cellular signaling pathways}

The genes that control cellular signaling pathways and regulate cell proliferation are key pleiotropic factors that may contribute to the polygenic profile of power athletes. Many of signaling pathways involve intracellular second messengers, that are released by the cell in response to exposure to extracellular signaling molecules.

One of the genes interacting in such a second messenger pathway is the CREM gene (location: 10p11.21) that encodes a cAMPresponsive element modulator. It is a bZIP transcription factor that binds to the cAMP responsive element found in many viral and cellular promoters. It is an important component of cAMP-mediated signal transduction during the spermatogenetic cycle, as well as other complex processes. CREM is highly expressed in testis, heart, brain, pancreas and retina. By performing three GWASs of elite Jamaican, African-American and Japanese sprint athletes and their matched controls and subsequent meta-analysis, Wang et al. (2014) found that the CREM A allele of the rs1531550 G/A polymorphism was significantly over-represented in elite sprinters compared with controls.

The next member of this group is the IP6K3 gene that encodes a protein belonging to the inositol phosphokinase (IPK) family. Inositol hexakisphosphate kinase 3 (IP6K3) generates inositol pyrophosphates (particularly IP7 - 5diphosphoinositolpentakisphosphate), which serves as the second messenger and regulates diverse cellular functions by controlling cellular signaling and interacts with other cellular components. The GWAS performed by Ischenko et al. (2015) found that the IP6K3 gene (location: 6p21.31) rs6942022 C allele was associated with power athlete status. Moreover, in the same study, these results were replicated in different subgroups of power athletes, indicating a real correlation existing with regard to this SNP. The analyses of mouse knockout models showed unchanged skeletal muscle mass and no resistance to the effects of high fat diet, however, ip $6 \mathrm{k} 3 \mathrm{-} /-$ mouse displayed neurological defects of motor learning and coordination. Further studies on the physiological role of rs6942022 SNP are required to establish its relevance for power athletes status.

The inositol phospholipid-calcium-protein kinase $C$ transduction pathway relies on the TRHR gene that encodes a thyrotropin releasing hormone receptor (location: 8q23.1). Upon binding to thyrotropin-releasing hormone (TRH), this receptor activates the inositol phospholipidcalcium-protein kinase $\mathrm{C}$ transduction pathway. TRH is a releasing hormone, produced by the hypothalamus, that stimulates the release of thyrotropin and prolactin from the anterior pituitary, thus having a fundamental role in the regulation of metabolic and hormonal functions. Mutations in the TRHR gene have been associated with generalized thyrotropin-releasing hormone resistance. The TRHR rs7832552 $\mathrm{T}$ allele has been shown to be associated with increased lean body mass in four independent cohorts (Liu et al., 2009), as well as with elite sprint/power athlete status in Japanese athletes (Miyamoto-Mikami et al., 2017).

The ARHGEF 28 gene encodes a member of the Rho guanine nucleotide exchange factor family, defined by their ability to catalyze the exchange of GDP for GTP on small GTPase proteins such as Rho family members. The protein encoded by the ARHGEF28 gene (location: 5q13.2) promotes activity of Rho GTPases that control signaling pathways regulating cell proliferation and movement and in this way is engaged in cell division and growth. In the GWAS of Russian athletes (strength athletes, endurance athletes and athletes from other sports with a strength component) and controls, the ARHGEF28 rs17664695 G allele was identified as being associated with elite strength athlete status (when compared with controls) (Egorova et al., 2015). The molecular basis of rs17664695 SNP is unknown and requires further studies.

The $A C V R 1 B$ gene encodes an activin A type IB receptor (location: 12q13.13). Activins are dimeric growth and differentiation factors which belong to the transforming growth factor-beta (TGF-beta) superfamily of structurally related signaling proteins. Activins signal is transmitted through a heteromeric complex of receptor serine kinases which include at least two type I and two type II receptors. This protein is a type I receptor which is essential for signaling. The ACVR1B rs2854464 A allele has previously been associated with increased muscle strength in healthy, nonathletic individuals (Windelinckx et al., 2011). In a 
relatively large cohort of athletes from Europe and South America, it has been shown that the ACVR1B rs2854464 A allele is associated with sprint/power athlete status in Caucasians, but not in Brazilian athletes (Voisin et al., 2016).

The compounds of cell surface are also crucial elements in many cellular signaling pathways, since from these elements many of them start. Cell surface heparan sulfate proteoglycans are complex molecules present in the cell membrane and extracellular matrix, which play pivotal roles in cell adhesion, migration, proliferation, as well as in signaling pathways. Mostly they are composed of one or more heparan sulfate chains covalently bound to the membraneassociated protein. GPC5 belongs to the GRIPS family that consists of glypican-related integral membrane proteoglycans linked to the cell surface via glycosyl phosphatidylinositol. These proteins may play a role in the control of cell division and growth regulation. In the GWAS performed by Egorova et al. (2015) the GPC5 gene (location: 13q32) rs852918 $\mathrm{T}$ allele was identified as associated with elite strength athlete status, probably influencing the complicated processes of cell division and growth.

Another membrane glycoprotein that mediates cell-cell signaling and plays a crucial role in the growth and development of organ systems as well as in the adult brain is the protein encoded by the NRG1 gene (location: $8 \mathrm{p} 12$ ). The product of the NRG1 gene may be produced in many different isoforms due to the alternative promoter usage and splicing. The alterations of the NRG1 function have been linked to diseases such as cancer, schizophrenia, and bipolar disorder (BPD). The GWAS study by Ischenko et al. (2015) showed that NRG1 rs17721043 A allele was associated with power athlete status. Considering the pleiotropic role of the NRG1 protein, the functional relevance of rs17721043 SNP remains elusive.

A specific type of cell-cell interaction is post-synaptic signaling. CLSTN2 (location: 3q23) encodes the synaptic protein calsyntenin 2 that is part of the components of the post-synaptic membrane and is located predominately in excitatory synapses giving CLSTN2 a role in intracellular post-synaptic signaling, potentially mediating specific responses in excitatory synaptic transmission. By comparing genetic profiles of two groups of elite Russian athletes (power and endurance athletes), and then between power athletes and controls, Gabdrakhmanova et al. (2015) identified CLSTN2 rs2194938 C allele as associated with power athlete status. Nevertheless, the detailed mechanism of rs2194938 SNP impact on athlete's organism still remains unclear.

GABA is the major inhibitory neurotransmitter in the mammalian brain where it acts at GABA receptors, which are ligand-gated chloride channels. GABRR1 is a member of a family of such chloride channels and is one of the major inhibitory neurotransmitter receptors in the central nervous system. The GABRR1 gene (location: 6q15) rs282114 A allele has been found in the group of SNPs that were correlated with power athlete status in the GWAS of Russian athletes. All SNPs in this group were characterized by increases in the frequency of the effect allele along with increases in the performance level of strength athletes, significant differences in allelic frequencies between strength and endurance athletes and at least one replication of association between these alleles and predisposition to other sports with a strength component (Egorova et al., 2015). Considering the physiological role of the GABRR1 receptor, it might be speculated that rs282114 SNP alters the neurotransmission process - however, it needs in vitro and in vivo confirmations.

\section{Conclusions}

It is well known that the interindividual variability of physical performance traits and the ability to become an elite athlete have a strong genetic basis. The genetic component to athletic potential and endurance or strength trainability is unquestionable, but the question remains which genes and DNA variants are involved and by which mechanisms and pathways they exert their effect.

All data presented in the current review provide evidence to support the notion that human physical performance may be influenced by genetic profiles, especially in power sports. Nevertheless, it needs to be highlighted that most of the cited above case-control and association studies have not yet been replicated in independent samples. Moreover, the problems of sample size, population stratification and quality of the genotype/phenotype measurement are also of great importance. Furthermore, it must be 
emphasized that each DNA locus can probably explain a very small proportion of the phenotypic variance. Therefore, very large sample sizes are needed to detect associations and various combinatorial approaches (with use of rare mutations and epigenetics markers) should be considered.

Studies included in the present review still represent only the first steps towards a better understanding of the genetic factors that influence power-related traits, thus further analyses with application of new DNA technologies (whole genome sequencing, GWAS, epigenomic, transcriptomic and proteomic profiling etc.) and bioinformatics to further analyze the genetic endowment of human physical abilities are necessary before implementation of research findings into practice.

\section{Acknowledgements}

The study was supported by National Science Centre of Poland (No. UMO-2017/27/B/NZ7/00204).

\section{References}

Ahmetov I, Hakimullina A, Lyubaeva E, Vinogradova O, Rogozkin V. Effect of HIF1A gene polymorphism on human muscle performance. Bull Exp Biol Med, 2008a; 146: 351-3

Ahmetov II, Druzhevskaya AM, Lyubaeva EV, Popov DV, Vinogradova OL, Williams AG. The dependence of preferred competitive racing distance on muscle fibre type composition and ACTN3 genotype in speed skaters. Exp Physiol, 2011; 96: 1302-10

Ahmetov II, Gavrilov DN, Astratenkova I V, Druzhevskaya AM, Malinin AV, Romanova EE, Rogozkin VA. The association of ACE, ACTN3 and PPARA gene variants with strength phenotypes in middle schoolage children. J Physiol Sci, 2013; 63: 79-85

Ahmetov II, Mozhayskaya IA, Flavell DM, Astratenkova I V, Komkova AI, Lyubaeva EV, Tarakin PP, Shenkman BS, Vdovina AB, Netreba AI, Popov DV, Vinogradova OL, Montgomery HE, Rogozkin VA. PPARalpha gene variation and physical performance in Russian athletes. Eur J Appl Physiol, 2006; 97: 103-8

Ahmetov II, Mozhayskaya IA, Lyubaeva EV, Vinogradova OL, Rogozkin VA. PPARG Gene polymorphism and locomotor activity in humans. Bull Exp Biol Med, 2008b; 146: 630-2

Ahmetov II, Naumov VA, Donnikov AE, Maciejewska-Karłowska A, Kostryukova ES, Larin AK, Maykova EV, Alexeev DG, Fedotovskaya ON, Generozov EV, Jastrzębski Z, Zmijewski P, Kravtsova OA, Kulemin NA, Leonska-Duniec A, Martykanova DS, Ospanova EA, Pavlenko AV, Podol'skaya AA, Sawczuk M, Alimova FK, Trofimov DY, Govorun VM, Cieszczyk P. SOD2 gene polymorphism and muscle damage markers in elite athletes. Free Radic Res, 2014; 48: 948-55

Barrès R, Yan J, Egan B, Treebak JT, Rasmussen M, Fritz T, Caidahl K, Krook A, O'Gorman DJ, Zierath JR. Acute exercise remodels promoter methylation in human skeletal muscle. Cell Metab, 2012; 15: 405-11

Ben-Zaken S, Eliakim A, Nemet D, Kassem E, Meckel Y. Increased prevalence of MnSOD genetic polymorphism in endurance and power athletes. Free Radic Res, 2013a; 47: 1002-8

Ben-Zaken S, Meckel Y, Nemet D, Eliakim A. Can IGF-I polymorphism affect power and endurance athletic performance? Growth Horm IGF Res, 2013b; 23: 175-8

Ben-Zaken S, Meckel Y, Nemet D, Eliakim A. IGF-I receptor 275124A>C (rs1464430) polymorphism and athletic performance. J Sci Med Sport, 2015; 18: 323-7

Ben-Zaken S, Meckel Y, Nemet D, Eliakim A. High prevalence of the IGF2 rs680 GG polymorphism among top-level sprinters and jumpers. Growth Horm IGF Res, 2017; 37: 26-30

Bonisławska I, Patyna A, Wilczyński J, Urbański R, Żychowska M. Assessment of fatigue and the overtraining syndrome in female spinning instructors based on a survey and on the expression of selected genes. Balt J Health Phys Activ, 2018; 10: 46-52

Boraita A, la Rosa A de, Heras ME, la Torre AI de, Canda A, Rabadán M, Díaz AE, González C, López M, Hernández M. Cardiovascular adaptation, functional capacity and Angiotensin-converting enzyme I/D 
polymorphism in elite athletes. Rev Esp Cardiol, 2010; 63: 810-9

Broos S, Windelinckx A, Mars G De, Huygens W, Peeters MW, Aerssens J, Vlietinck R, Beunen GP, Thomis MA. Is PPAR $\alpha$ intron $7 \mathrm{G} / \mathrm{C}$ polymorphism associated with muscle strength characteristics in nonathletic young men? Scand J Med Sci Sports, 2013; 23: 494-500

Cauci S, Santolo M Di, Ryckman KK, Williams SM, Banfi G. Variable number of tandem repeat polymorphisms of the interleukin-1 receptor antagonist gene IL-1RN: a novel association with the athlete status. BMC Med Genet, 2010; 11: 29

Chen C, Sun Y, Liang H, Yu D, Hu S. A meta-analysis of the association of CKM gene rs8111989 polymorphism with sport performance. Biol Sport, 2017; 34: 323-330

Chiu L-L, Wu Y-F, Tang M-T, Yu H-C, Hsieh L-L, Hsieh SS-Y. ACTN3 genotype and swimming performance in Taiwan. Int J Sports Med, 2011; 32: 476-80

Cieszczyk P, Eider J, Arczewska A, Ostanek M, Leońska-Duniec A, Sawczyn S, Ficek K, Jascaniene N, Kotarska K, Sygit K. The HIF1A gene Pro582Ser polymorphism in polish power-orientated athletes. Biol Sport, 2011a; 28: 111-114

Cieszczyk P, Eider J, Ostanek M, Arczewska A, Leońska-Duniec A, Sawczyn S, Ficek K, Krupecki K. Association of the ACTN3 R577X Polymorphism in Polish Power-Orientated Athletes. J Hum Kinet, 2011b; 28: 55-61

Cieszczyk P, Ostanek M, Leońska-Duniec A, Sawczuk M, Maciejewska A, Eider J, Ficek K, Sygit K, Kotarska K. Distribution of the AMPD1 C34T polymorphism in Polish power-oriented athletes. J Sports Sci, 2012; 30: 31-35

Costa AM, Silva AJ, Garrido ND, Louro H, Oliveira RJ de, Breitenfeld L. Association between ACE D allele and elite short distance swimming. Eur J Appl Physiol, 2009; 106: 785-90

Deason M, Scott R, Irwin L, Macaulay V, Fuku N, Tanaka M, Irving R, Charlton V, Morrison E, Austin K, Pitsiladis YP. Importance of mitochondrial haplotypes and maternal lineage in sprint performance among individuals of West African ancestry. Scand J Med Sci Sports, 2012; 22: 217-23

Drozdovska S, Dosenko V, Ilyin V, Filippov M, Kuzmina L. Allelic Polymorphism of Endothelial No-Synthase (eNOS) Association with Exercise-Induced Hypoxia Adaptation. Balt J Heal Phys Act, 2009; 1: 10-14

Drozdovska SB, Dosenko VE, Ahmetov II, Ilyin VN. The association of gene polymorphisms with athlete status in ukrainians. Biol Sport, 2013; 30: 163-7

Druzhevskaya AM, Ahmetov II, Astratenkova I V, Rogozkin VA. Association of the ACTN3 R577X polymorphism with power athlete status in Russians. Eur J Appl Physiol, 2008; 103: 631-4

Egorova ES, Borisova A V, Mustafina LJ, Arkhipova AA, Gabbasov RT, Druzhevskaya AM, Astratenkova IV, Ahmetov II. The polygenic profile of Russian football players. J Sports Sci, 2014; 32: 1286-93

Egorova ES, Ischenko DS, Kulemin NA, Galeeva AA, Kostryukova ES, Alexeev DG, Gabdrakhmanova LJ, Larin AK, Generozov E V, Ospanova EA, Pavlenko A V, Govorun VM, Ahmetov II. Genome-wide association study of elite strength athlete status in Russians. Eur J Hum Genet, 2015; 23: 468-469

Eider J, Cieszczyk P, Leońska-Duniec A, Maciejewska A, Sawczuk M, Ficek K, Kotarska K. Association of the 174 G/C polymorphism of the IL6 gene in Polish power-orientated athletes. J Sports Med Phys Fitness, 2013; 53: 88-92

Eynon N, Alves AJ, Meckel Y, Yamin C, Ayalon M, Sagiv M, Sagiv M. Is the interaction between HIF1A P582S and ACTN3 R577X determinant for power/sprint performance? Metabolism, 2010a; 59: 861-5

Eynon N, Duarte JA, Oliveira J, Sagiv M, Yamin C, Meckel Y, Sagiv M, Goldhammer E. ACTN3 R577X Polymorphism and Israeli Top-level Athletes. Int J Sports Med, 2009; 30: 695-698

Eynon N, Meckel Y, Sagiv M, Yamin C, Amir R, Sagiv M, Goldhammer E, Duarte JA, Oliveira J. Do PPARGC1A and PPAR $\alpha$ polymorphisms influence sprint or endurance phenotypes? Scand J Med Sci Sports, 2010b; 20: e145-e150

Eynon N, Ruiz JR, Meckel Y, Santiago C, Fiuza-Luces C, Gómez-Gallego F, Oliveira J, Lucia A. Is the -174 C/G polymorphism of the IL6 gene associated with elite power performance? A replication study with two different Caucasian cohorts. Exp Physiol, 2011; 96: 156-62

Fedotovskaya ON, Danilova AA, Akhmetov II. Effect of AMPD1 gene polymorphism on muscle activity in humans. Bull Exp Biol Med, 2013; 154: 489-91

(C) Editorial Committee of Journal of Human Kinetics 
Gabbasov RT, Arkhipova AA, Borisova A V, Hakimullina AM, Kuznetsova A V, Williams AG, Day SH, Ahmetov II. The HIF1A gene Pro582Ser polymorphism in Russian strength athletes. J Strength Cond Res, 2013; 27: 2055-8

Gabdrakhmanova LJ, Ischenko DS, Kulemin NA, Popov D V, Galeeva AA, Kostryukova ES, Alexeev DG, Egorova ES, Larin AK, Generozov E V, Ospanova EA, Pavlenko A V, Akimov EB, Vinogradova OL, Govorun VM, Ahmetov II. The difference in genomic profiles between endurance and power athletes. Eur J Hum Genet, 2015; 23: 471

Ginevičienė V, Jakaitiene A, Aksenov MO, Aksenova A V., Druzhevskaya AM, Astratenkova I V, Egorova ES, Gabdrakhmanova LJ, Tubelis L, Kucinskas V, Utkus A. Association analysis of ACE, ACTN3 and PPARGC1A gene polymorphisms in two cohorts of European strength and power athletes. Biol Sport, 2016; 33: 199-206

Ginevičienė V, Jakaitienė A, Pranculis A, Milašius K, Tubelis L, Utkus A. AMPD1 rs17602729 is associated with physical performance of sprint and power in elite Lithuanian athletes. BMC Genet, 2014; 15: 58

Ginevičienè V, Pranckevičienè E, Milašius K, Kučinskas V. Relating fitness phenotypes to genotypes in Lithuanian elite athletes. Acta medica Litu, 2010; 17: 1-10

Gomez-Gallego F, Ruiz JR, Buxens A, Artieda M, Arteta D, Santiago C, Rodríguez-Romo G, Lao JI, Lucia A. The $-786 \mathrm{~T} / \mathrm{C}$ polymorphism of the NOS3 gene is associated with elite performance in power sports. Eur J Appl Physiol, 2009a; 107: 565-569

Gomez-Gallego F, Santiago C, González-Freire M, Yvert T, Muniesa CA, Serratosa L, Altmäe S, Ruiz JR, Lucia A. The C allele of the AGT Met235Thr polymorphism is associated with power sports performance. Appl Physiol Nutr Metab, 2009b; 34: 1108-11

Guilherme JPLF, Lancha AH. Single Nucleotide Polymorphisms in Carnosinase Genes (CNDP1 and CNDP2) are Associated With Power Athletic Status. Int J Sport Nutr Exerc Metab, 2017; 27: 533-542

Guilherme JPLF, Silva MS, Bertuzzi R, Lancha Junior AH. The AGTR2 rs11091046 (A>C) polymorphism and power athletic status in top-level Brazilian athletes. J Sports Sci, 2018; 36: 2327-2332

Ischenko DS, Galeeva AA, Kulemin NA, Kostryukova ES, Alexeev DG, Egorova ES, Gabdrakhmanova LJ, Larin AK, Generozov E V, Ospanova EA, Pavlenko A V, Govorun VM, Ahmetov II. Genome-wide association study of elite power athlete status. Eur J Hum Genet, 2015; 23: 472

Kim C-H, Cho J-Y, Jeon JY, Koh YG, Kim Y-M, Kim H-J, Park M, Um H-S, Kim C. ACE DD genotype is unfavorable to Korean short-term muscle power athletes. Int J Sports Med, 2010; 31: 65-71

Liu X-G, Tan L-J, Lei S-F, Liu Y-J, Shen H, Wang L, Yan H, Guo Y-F, Xiong D-H, Chen X-D, Pan F, Yang T-L, Zhang Y-P, Guo Y, Tang NL, Zhu X-Z, Deng H-Y, Levy S, Recker RR, Papasian CJ, Deng H-W. Genomewide association and replication studies identified TRHR as an important gene for lean body mass. Am J Hum Genet, 2009; 84: 418-23

Lucia A, Gómez-Gallego F, Santiago C, Bandrés F, Earnest C, Rabadán M, Alonso J, Hoyos J, Córdova A, Villa G, Foster C. ACTN3 Genotype in Professional Endurance Cyclists. Int J Sports Med, 2006; 27: 880-884

Maciejewska-Karlowska A, Sawczuk M, Cieszczyk P, Zarebska A, Sawczyn S. Association between the Pro12Ala polymorphism of the peroxisome proliferator-activated receptor gamma gene and strength athlete status. PLoS One, 2013; 8: e67172

Maciejewska A, Sawczuk M, Cieszczyk P, Mozhayskaya IA, Ahmetov II. The PPARGC1A gene Gly482Ser in Polish and Russian athletes. J Sports Sci, 2012; 30: 101-113

Massidda M, Vona G, Calò CM. Association Between the ACTN3 R577X Polymorphism and Artistic Gymnastic Performance in Italy. Genet Test Mol Biomarkers, 2009; 13: 377-380

Mikami E, Fuku N, Murakami H, Tsuchie H, Takahashi H, Ohiwa N, Tanaka H, Pitsiladis YP, Higuchi M, Miyachi M, Kawahara T, Tanaka M. ACTN3 R577X genotype is associated with sprinting in elite Japanese athletes. Int J Sports Med, 2014; 35: 172-7

Mikami E, Fuku N, Takahashi H, Ohiwa N, Pitsiladis YP, Higuchi M, Kawahara T, Tanaka M. Polymorphisms in the control region of mitochondrial DNA associated with elite Japanese athlete status. Scand J Med Sci Sports, 2013; 23: 593-9

Mikami E, Fuku N, Takahashi H, Ohiwa N, Scott RA, Pitsiladis YP, Higuchi M, Kawahara T, Tanaka M. Mitochondrial haplogroups associated with elite Japanese athlete status. Br J Sports Med, 2011; 45: 11791183 
Miyamoto-Mikami E, Fujita Y, Murakami H, Ito M, Miyachi M, Kawahara T, Fuku N. CNTFR Genotype and Sprint/power Performance: Case-control Association and Functional Studies. Int J Sports Med, 2016; 37: 411-7

Miyamoto-Mikami E, Murakami H, Tsuchie H, Takahashi H, Ohiwa N, Miyachi M, Kawahara T, Fuku N. Lack of association between genotype score and sprint/power performance in the Japanese population. J Sci Med Sport, 2017; 20: 98-103

Mustafina LJ, Naumov VA, Cieszczyk P, Popov DV, Lyubaeva EV, Kostryukova ES, Fedotovskaya ON, Druzhevskaya AM, Astratenkova I V, Glotov AS, Alexeev DG, Mustafina MM, Egorova ES, Maciejewska-Karłowska A, Larin AK, Generozov EV, Nurullin RE, Jastrzębski Z, Kulemin NA, Ospanova EA, Pavlenko AV, Sawczuk M, Akimov EB, Danilushkina AA, Zmijewski P, Vinogradova OL, Govorun VM, Ahmetov II. AGTR2 gene polymorphism is associated with muscle fibre composition, athletic status and aerobic performance. Exp Physiol, 2014; 99: 1042-52

Myerson S, Hemingway H, Budget R, Martin J, Humphries S, Montgomery H. Human angiotensin Iconverting enzyme gene and endurance performance. J Appl Physiol, 1999; 87: 1313-1316

Naumov VA, Ahmetov II, Larin AK, Generozov EV, Kulemin NA, Ospanova EA, Pavlenko A V, Kostryukova ES, Alexeev DG, Govorun VM. Genome-wide association analysis identifies a locus on DMD (dystrophin) gene for power athlete status in Russians. Eur J Hum Genet, 2014; 22: 502

Nazarov IB, Woods DR, Montgomery HE, Shneider OV, Kazakov VI, Tomilin NV, Rogozkin VA. The angiotensin converting enzyme I/D polymorphism in Russian athletes. Eur J Hum Genet, 2001; 9: 797801

Niemi A-K, Majamaa K. Mitochondrial DNA and ACTN3 genotypes in Finnish elite endurance and sprint athletes. Eur J Hum Genet, 2005; 13: 965-9

Papadimitriou ID, Papadopoulos C, Kouvatsi A, Triantaphyllidis C. The ACTN3 gene in elite Greek track and field athletes. Int J Sports Med, 2008; 29: 352-5

Papadimitriou ID, Papadopoulos C, Kouvatsi A, Triantaphyllidis C. The ACE I/D polymorphism in elite Greek track and field athletes. J Sports Med Phys Fitness, 2009; 49: 459-63

Roth SM, Walsh S, Liu D, Metter EJ, Ferrucci L, Hurley BF. The ACTN3 R577X nonsense allele is underrepresented in elite-level strength athletes. Eur J Hum Genet, 2008; 16: 391-4

Ruiz JR, Buxens A, Artieda M, Arteta D, Santiago C, Rodríguez-Romo G, Lao JI, Gómez-Gallego F, Lucia A. The $-174 \mathrm{G} / \mathrm{C}$ polymorphism of the IL6 gene is associated with elite power performance. J Sci Med Sport, 2010; 13: 549-553

Sawczuk M, Banting LK, Cięszczyk P, Maciejewska-Karłowska A, Zarębska A, Leońska-Duniec A, Jastrzębski Z, Bishop DJ, Eynon N. MCT1 A1470T: a novel polymorphism for sprint performance? J Sci Med Sport, 2015; 18: 114-8

Sawczuk M, Maciejewska-Karlowska A, Cieszczyk P, Skotarczak B, Ficek K. Association of the ADRB2 Gly16Arg and Glu27Gln polymorphisms with athlete status. J Sports Sci, 2013; 31: 1535-44

Sessa F, Chetta M, Petito A, Franzetti M, Bafunno V, Pisanelli D, Sarno M, Iuso S, Margaglione M. Gene polymorphisms and sport attitude in Italian athletes. Genet Test Mol Biomarkers, 2011; 15: 285-90

Shahmoradi S, Ahmadalipour A, Salehi M. Evaluation of ACE gene I/D polymorphism in Iranian elite athletes. Adv Biomed Res, 2014; 3: 207

Terruzzi I, Senesi P, Montesano A, Torre A La, Alberti G, Benedini S, Caumo A, Fermo I, Luzi L. Genetic polymorphisms of the enzymes involved in DNA methylation and synthesis in elite athletes. Physiol Genomics, 2011; 43: 965-73

Voisin S, Cieszczyk P, Pushkarev VP, Dyatlov DA, Vashlyayev BF, Shumaylov VA, Maciejewska-Karlowska A, Sawczuk M, Skuza L, Jastrzebski Z, Bishop DJ, Eynon N. EPAS1 gene variants are associated with sprint/power athletic performance in two cohorts of European athletes. BMC Genomics, 2014; $15: 382$

Voisin S, Guilherme JPFL, Yan X, Pushkarev VP, Cieszczyk P, Massidda M, Calò CM, Dyatlov DA, Kolupaev VA, Pushkareva YE, Maciejewska A, Sawczuk M, Lancha AH, Artioli GG, Eynon N. ACVR1B rs2854464

(C) Editorial Committee of Journal of Human Kinetics 
Is Associated with Sprint/Power Athletic Status in a Large Cohort of Europeans but Not Brazilians. PLoS One, 2016; 11: e0156316

Wang G, Mikami E, Chiu L-L, Perini A DE, Deason M, Fuku N, Miyachi M, Kaneoka K, Murakami H, Tanaka M, Hsieh L-L, Hsieh SS, Caporossi D, Pigozzi F, Hilley A, Lee R, Galloway SDR, Gulbin J, Rogozkin VA, Ahmetov II, Yang N, North KN, Ploutarhos S, Montgomery HE, Bailey MES, Pitsiladis YP. Association analysis of ACE and ACTN3 in elite Caucasian and East Asian swimmers. Med Sci Sports Exerc, 2013a; 45: 892-900

Wang G, Padmanabhan S, Miyamoto-Mikami E, Fuku N, Tanaka M, Miyachi M, Murakami H, Cheng Y-C, Mitchell BD, Austin KG, Pitsiladis YP. GWAS of Elite Jamaican, African American and Japanese Sprint Athletes. Med Sci Sport Exerc, 2014; 46: 596-598

Wang G, Padmanabhan S, Wolfarth B, Fuku N, Lucia A, Ahmetov II, Cieszczyk P, Collins M, Eynon N, Klissouras V, Williams A, Pitsiladis Y. Genomics of elite sporting performance: what little we know and necessary advances. Adv Genet, 2013b; 84: 123-49

Windelinckx A, De Mars G, Huygens W, Peeters MW, Vincent B, Wijmenga C, Lambrechts D, Delecluse C, Roth SM, Metter EJ, Ferrucci L, Aerssens J, Vlietinck R, Beunen GP, Thomis MA. Comprehensive fine mapping of chr12q12-14 and follow-up replication identify activin receptor 1B (ACVR1B) as a muscle strength gene. Eur J Hum Genet. England, 2011; 19: 208-215

Woods D, Hickman M, Jamshidi Y, Brull D, Vassiliou V, Jones A, Humphries S, Montgomery H. Elite swimmers and the D allele of the ACE I/D polymorphism. Hum Genet, 2001; 108: 230-2

Yang N, MacArthur DG, Gulbin JP, Hahn AG, Beggs AH, Easteal S, North K. ACTN3 Genotype Is Associated with Human Elite Athletic Performance. Am J Hum Genet, 2003; 73: 627-631

Yvert TP, Zempo H, Gabdrakhmanova LJ, Kikuchi N, Miyamoto-Mikami E, Murakami H, Naito H, Cieszczyk P, Leznicka K, Kostryukova ES, Alexeev DG, Egorova ES, Maciejewska-Skrendo A, Larin AK, Generozov E V., Kulemin NA, Ospanova EA, Pavlenko A V., Sawczuk M, Zmijewski P, Lulinska-Kuklik E, Govorun VM, Miyachi M, Ahmetov II, Fuku N. AGTR2 and sprint/power performance: a case-control replication study for rs11091046 polymorphism in two ethnicities. Biol Sport, 2018; 35:105-109

Zarebska A, Ahmetov II, Sawczyn S, Weiner AS, Kaczmarczyk M, Ficek K, Maciejewska-Karlowska A, Sawczuk M, Leonska-Duniec A, Klocek T, Voronina EN, Boyarskikh UA, Filipenko ML, Cieszczyk P. Association of the MTHFR 1298A\&gt;C (rs1801131) polymorphism with speed and strength sports in Russian and Polish athletes. J Sports Sci, 2014; 32: 375-82

Zarebska A, Sawczyn S, Kaczmarczyk M, Ficek K, Maciejewska-Karłowska A, Sawczuk M, Leońska-Duniec A, Eider J, Grenda A, Cięszczyk P. Association of rs699 (M235T) polymorphism in the AGT gene with power but not endurance athlete status. J Strength Cond Res, 2013; 27: 2898-903

\section{Corresponding author:}

\section{Paweł Cięszczyk}

Department of Molecular Biology, Faculty of Physical Education,

Gdansk University of Physical Education and Sport

Kazimierza Górskiego 1, 80-336 Gdańsk, Poland

E-mail: cieszczyk@poczta.onet.pl 